\title{
CONSTITUIÇÃO IDENTITÁRIA E MECANISMOS DE (RE)PRODUÇÃO DA ESPACIALIDADE RIBEIRINHA
}

\author{
Cícero Bezerra da Silva \\ Universidade Federal de Sergipe (UFS) \\ Programa de Pós-graduação em Geografia, São Cristóvão, SE, Brasil.
} cicerogeografia016@gmail.com

\begin{abstract}
RESUMO
O artigo apresenta a constituição das identidades inerente à espacialidade ribeirinha no Sertão do Baixo Rio São Francisco, entre os estados de Alagoas e Sergipe. Para isso, toma-se o rio como um espaço de referência identitária em que coexistem formas e relações de apropriações simbólica e material que reverberam no processo de constituição identitária. Buscou-se em Haesbaert (1997; 1999), Castells (2006), Hall (2006) e Cruz (2006; 2007) a leitura necessária à compreensão das identidades como um processo dinâmico e em constante construção. Como instrumentais para a investigação lançou-se mão do desenvolvimento de trabalhos de campo, de entrevistas semiestruturas e de observações associadas à paisagem produzida e vivenciada no contexto dos lugares de fala dos ribeirinhos. Dessa construção, embasados em Bassand (1990), foram aprendidas cinco tipologias identitárias, a saber: i) os tradicionalistas; ii) os migrantes potenciais; iii) os apáticos e resignados; iv) modernizadores e v) os regionalistas. Essa classificação demostra a dinamicidade dos usos e apropriações da espacialidade ribeirinha e das formas de relacionamento com o rio São Francisco tomado, para uns, como lugar e, para outros, como um território.
\end{abstract}

Palavras-chave: Identidades. Natureza. Cultura. Espacialidade Ribeirinha.

\section{IDENTITY CONSTITUTION AND MECHANISMS FOR (RE) PRODUCTION OF RIBEIRINHA SPACIALITY}

\begin{abstract}
The article presents the constitution of identities inherent to the riverine spatiality in the Sertão of the Lower São Francisco River, between the states of Alagoas and Sergipe. For this, the river is taken as a space of identity reference in which coexist forms and relations of symbolic and material appropriations that reverberate in the process of identity constitution. Haesbaert (1997; 1999), Castells (2006), Hall (2006), and Cruz (2006; 2007) provided the necessary reading for understanding identities as a dynamic process in constant construction. As instruments for the investigation, we used the development of fieldwork, semi-structured interviews, and observations associated with the landscape produced and experienced in the context of the riverside dwellers' places of speech. From this construction, based on Bassand (1990), five identity typologies were learned, namely: i) the traditionalists; ii) the potential migrants; iii) the apathetic and resigned; iv) the modernizers, and $v$ ) the regionalists. This classification demonstrates the dynamics of the uses and appropriations of the riverside spatiality and the forms of relationship with the São Francisco River, taken, for some, as a place and, for others, as a territory.
\end{abstract}

Keywords: Identities. Nature. Culture. Riparian Spatiality.

\section{INTRODUÇÃO}

Pensada como construção social, a compreensão das identidades na complexa trama da contemporaneidade tem requerido mais que a leitura dos resultados do perfil cultural de uma região ou lugar. No transcurso da constituição de lugares virtualmente mundiais e de lugares não locais (SANTOS, 2002), identidade e cultura só são passiveis de compreensão pela leitura das transformações que ocorrem no mundo como extensão da própria realidade local, ou seja, parafraseando Michel Serres (1994, p. 12), o "ser aí expande-se". Trata-se de um entrelace de similitudes e diferenças que caracterizam, dão forma e sentidos a uma construção que é histórica e dinâmica em diferentes tempos e espaços.

$\begin{array}{llllll}\text { Caminhos de Geografia } & \text { Uberlândia-MG } & \text { v. 23, n. } 85 & \text { fev./2022 } & \text { p. 42-53 } & \text { Página } 42\end{array}$


Sendo dinâmica no tempo e no espaço a constituição identitária, ou de outro modo, o ato da identificação, envolve mudanças e permanências. Envolve, para Stuart Hall (2006), tradições e traduções. O que permanece são as tradições, o amálgama das relações primeiras dos povos com os seus lugares em diferentes dimensões escalares, o enraizamento, formas do passado e do presente que possuem sentido existencial. Por outro lado, as traduções dizem mais sobre travessias de percursos, ou seja, o itinerário a ser seguido, o devir, são os sonhos, as aspirações. É, assim, a perspectiva da mudança, uma dialética do que foi, do que se é e do que pode vir a ser.

Tomada pelo signo da existencialidade e das relações do lugar-mundo vivido, as identidades são geradoras de relações espaciais que se consubstanciam como modos simbólicos e materiais de apropriação e identificação referendadas na natureza pela cultura dos povos. Enquanto mecanismo de produção e reprodução espacial, as identidades significam e ressignificam o viver e o habitar, os usos do espaço e os significados que historicamente lhes foram atribuídos. Dinâmicas, fluidas e até mesmo evanescentes, as identidades estão em constante processo de caracterização e agregação de sentidos aos povos e às suas formas, que são, fundamentalmente, produtores de espacialidades.

Ao serem desveladas como relações espaciais, o ato da identificação e do pertencimento é gerador de espaços de referência identitária (POCHE, 1983; HAESBAERT, 1997; CRUZ, 2006), caracterizados de acordo com o nível cultural de cada povo, seus modos de vida e relacionamento com a natureza, assim como pelas transformações que se desvencilham no cotidiano e para além dele.

Desse modo, no presente artigo, tem-se por intenção apresentar o contexto de constituição das identidades ribeirinhas no/do Sertão do Baixo Rio São Francisco (SBRSF) e das respectivas espacialidades como um processo que está sempre em construção, remodelando-se de acordo com o contexto cultural, ambiental e econômico ao qual o rio e seus povos se encontram inseridos. De modo mais específico, essas espacialidades dizem respeito aos modos de produção, reprodução e organização dos espaços de vida, apresentados tanto pelos sentidos de lugar quanto pelos sentidos de território. Pensadas e moldadas pelas dimensões simbólica e material, busca-se entender a construção das identidades como processo social dinâmico, fluido e em constante (re)produção, que se reverbera no contexto das espacialidades ribeirinhas.

Como recorte territorial utiliza-se como espaço de referência as comunidades, sedes municipais e povoados localizados às margens alagoana e sergipana do rio São Francisco e que estão inseridas no domínio das terras semiáridas, localizadas a jusante do lago da Usina Hidroelétrica de Xingó. Para a definição do sertão semiárido fez-se uso da classificação e delimitação do Polígono das Secas apresentado pela Superintendência de Desenvolvimento do Nordeste (2017). Todavia, lembramos a multiplicidade de significações do termo "sertão" envolto às relações culturais, identitárias e históricas as quais o mesmo é empregado.

Os sentidos formadores das identidades ribeirinhas e de suas respectivas espacialidades no Sertão do Baixo Rio São Francisco se associam a multiplicidade de povos, paisagens, lugares e territórios que se encontram em constante transformação. Características essas que, para Stoll, et al (2019, p. 28), devem ser entendidas [...] " não apenas como dados do ecossistema, mas sim como dinâmicas participando de um processo em perpétuo devir, acionado por várias agências, humanas e não humanas" (STOLL et al, 2019, p. 28) e, também, entre simbolismo/subjetivismo e materialidade.

Para assim discutir essas questões, a construção textual está organizada em três momentos: incialmente delineiam-se algumas considerações teóricas sobre a(s) identidade(s) pensada(s) como resultado de construções sociais no tempo e no espaço. Na segunda parte contextualiza-se o Sertão do Baixo Rio São Francisco como espaço de referência identitária em que são produzidas espacialidades múltiplas caracterizadas pelos modos de significar a natureza/espaço e por apropriações simbólicas e materiais. Esses modos de apropriação são reveladores de identidades que se entremeiam entre o rural e o urbano e entre tradições e traduções e, por último, antecedendo as considerações finais, buscamos demostrar como se dá a (re)produção das espacialidades ribeirinhas no Sertão do Baixo Rio São Francisco.

Essa leitura se deu em face ao contexto das falas expressas pelas "gentes" do rio São Francisco, um processo interpretativo daquilo que se relata e, simultaneamente, daquilo que foi observado nos lugares de fala. Assim, buscou-se aproximar natureza e processos culturais como elementos constitutivos das identidades. Com esse viés interpretativo, concebeu-se o rio São Francisco como um espaço de referência não tão somente pelas relações do presente e da cultura local, mas como 
espaço dinâmico que abriga sedimentos de histórias de vida reveladoras das espacialidades de ser e estar no rio.

Metodologicamente, esta leitura se iniciou pela revisão bibliográfica pertinente à temática, observação dirigida e análise de trinta e oito (38) entrevistas realizadas em comunidades ribeirinho-sertanejas entre os anos de 2018 e 2019. A definição da amostra da pesquisa foi realizada segundo o critério da amostragem por variedade de tipos, um "processo de seleção que se dá segundo o arbítrio e o interesse científico do pesquisador, cuja resolução, no entanto, embora definida como livre eleição [...], deve vir acompanhada de suas justificativas junto ao projeto" (TURATO, 2003, p. 365). Esse tipo de amostragem apresenta como principal característica ao menos uma variável comum entre todos os sujeitos escolhidos, ou seja, "a característica-chave que os une é o próprio tema do trabalho" (TURATO, 2003, p. 365). Assim, a constituição da amostra tem na vivência com o rio São Francisco o elemento definidor e central comum a todos os entrevistados.

Os entrevistados componentes da amostra se caracterizam, sobretudo, por pescadores, barqueiros, pequenos agricultores - lavradores -, artesãos, donas de casa, proprietários de bares às margens do rio, trabalhadores voltados ao público do turismo e do lazer que residem ou sustentam interação direta com o rio São Francisco e, também, aposentados e pensionistas. Em menor proporção, obtevese acesso a líderes de associação comunitária de moradores, presidente de colônia de pescadores, secretário municipal, professores e estudantes locais.

Para a necessária argumentação, a revisão bibliográfica foi sucedida pelo acesso e consequente análise de dados secundários inerentes ao contexto social dos municípios e das comunidades, quais sejam: Instituto Brasileiro de Geografia e Estatística, Atlas Nacional do Desenvolvimento Humano, Centro de Documentação Dom Tomás Balduino (CEDOC), da Comissão Pastoral da Terra e a central de documentação do Comitê da Bacia Hidrográfica do Rio São Francisco.

\section{IDENTIDADES, TEMPO-ESPAÇO E CONSTRUÇÃO SOCIAL}

A compreensão das identidades como uma construção histórica e social no tempo e no espaço é apresentada por Hall (2006, p. 38), para quem esta é [...] "realmente, algo formado ao longo do tempo, através de processos inconscientes [...]. Ela [a identidade] permanece sempre incompleta, está sempre em processo, sempre sendo formada". Como construção cultural, as identidades se revelam não tão somente pelo momento e acontecimentos do presente, se revelam muito mais pelos processos históricos e transformações as quais determinados grupos sociais foram e são submetidos.

A identidade é, realmente, algo construído e moldado no/pelo tempo no contexto cultural de cada sociedade ou grupo que a envolve, se apresenta como algo dinâmico, estando sempre susceptível ao processo de mudança, e isso não implica perder as raízes que a originaram. A noção de tempo adensa as identidades, tempo passado, tempo presente e aspirações futuras. "Assim, ao invés de falar da identidade como uma coisa acabada, deveríamos falar de identificação, e vê-la como um processo em andamento" (HALL, 2006, p. 39).

De acordo com Haesbaert (1999), a construção dos sentidos da identidade é permeada pela temporalidade, [...] "tratando-se sempre de uma identificação em curso, e por estar sempre em processo/relação, ela nunca é una, mas múltipla" (HAESBAERT, 1999, p. 175). Como processo fluido, dinâmico, o tratar da identidade ou de processos de identificação envolve a leitura de mudanças e permanências de significações e ressignificações, de modos de ser e do devir. De modo dialógico ao posicionamento de Haesbaert (1999), Cruz (2007, p. 270) considera a identidade como resultante de "uma construção histórica e relacional dos significados sociais e culturais que norteiam o processo de distinção e identificação de um indivíduo ou de um grupo".

Castells, em $O$ Poder da Identidade, atém-se à concepção de que a identidade deve ser pensada como "o processo de construção de significados com base em um atributo cultural, ou ainda em um conjunto de atributos culturais inter-relacionados, o(s) qual(ais) prevalece $(\mathrm{m})$ sobre outras fontes de significados" (CASTELLS, 2006, p. 22). Esse conjunto de atributos culturais está associado à matériaprima ou à base necessária à existência da identidade ou do processo de identificação. Nos termos do autor (Idem), depreende-se o entendimento de que:

A construção de identidades vale-se da matéria-prima fornecida pela história, geografia, biologia, instituições produtivas e reprodutivas, pela memória coletiva e por fantasias pessoais, pelos aparatos de poder e revelações de cunho religioso. Porém, todos esses materiais são processados pelos indivíduos, grupos sociais e

$\begin{array}{llllll}\text { Caminhos de Geografia } & \text { Uberlândia-MG } & \text { v. 23, n. } 85 & \text { fev./2022 } & \text { p. 42-53 } & \text { Página } 44\end{array}$


sociedades que reorganizam seu significado em função de tendências sociais e projetos culturais enraizados em sua estrutura social, bem como em sua visão de tempo/espaço (CASTELLS, 2006, p 23).

Consonante, as contribuições de Castells (1999), Haesbaert (1999), Hall (2006) e Cruz $(2006,2007)$ remetem ao princípio da temporalidade como substantiva no processo de constituição identitária. Acordam que ela é moldada no tempo e no espaço pela cultura produzida e afeiçoada nas experiências de vida, nas relações de poder, na apropriação da natureza e das formas construídas em seu sentido mais amplo; envolve a relação dialógica local-global como experiência do lugarmundo, extensão do ser-aí para o ser alhures e que, de modo algum, se caracteriza como um processo apático aos acontecimentos externos à realidade de cada indivíduo ou grupo com vistas à introspecção do ser. Dialogicamente, Cruz (2006, p. 31) demostra que,

Não é possível estudar a identidade de qualquer grupo social apenas com base na sua cultura, ou no seu modo de vida, nas suas representações de forma introvertida e auto-referenciada, pois as identidades e os sentimentos de pertencimento são construídos de maneira relacional e contrastiva e muitas vezes conflitiva entre uma auto-identidade (auto-atribuição, auto-reconhecimento) e uma hetero-identidade (atribuição e reconhecimento pelo "outro"). São nessas teias complexas de valorações e significados de reconhecimento e alteridade que se estabelece o diálogo e o conflito entre os grupos, forjando as identidades (CRUZ, 2006, p. 31).

Identidade e cultura são, pois construções individuais e coletivas, resultado das vivências, das experiências e dos sentidos que cada sujeito ou grupo atribui aos seus espaços. Identidade e cultura são elementos de representação simbólica e material que identificam, diferenciam e afirmam lugares, gentes, povos. Diferenciam o "eu" e o "outro", o "meu lugar" frente ao "lugar do outro" pela produção e reprodução de estruturas não tão somente materiais e tampouco se restringem ao simbolismo ou imaterialidade. Há que se perceber na constituição das identidades e, por conseguinte, da cultura o amálgama entre uma dimensão que é simbólica subjetiva e a realidade material.

Dessa dimensão, acresce-se que:

A identidade é construída subjetivamente, baseada nas representações, nos discursos, nos sistemas de classificação simbólica, embora não seja algo puramente subjetivo e não se restrinja à 'textualidade' e ao 'simbólico'. Ela não é uma construção puramente imaginária que despreza a realidade material e objetiva das experiências e das práticas sociais como muitos afirmam, e nem tão pouco é algo materialmente dado, objetivo, uma essência imutável, fixa e definitiva (CRUZ, 2007, p. 263).

Reverberando o contexto dialético das identidades como fundamentadas em similitudes e diferenças, entre "o eu" e "o outro" como relação de alteridade, Benitez e Levi (2009) assinalam que:

La identidad es una construcción social reforzada por un discurso que lo retroalimenta, que se apoya en criterios y rasgos distintivos para afirmar y reafirmar similitudes y diferencias. [...] Aunque dichos rasgos pudiesen contemplar también aspectos de género, religión, grupo étnico, ocupación, el carácter de originario o avecindado es determinante en la forma como se perciben a sí mismos y al otro, en la forma como se construye la colectividad y se establece la alteridad (2009, p. 125).

Assim sendo, a ideia de identidade envolve também as relações de diferenciação entre o "eu" e o "outro", entre escalas e lugares, seja pelas distinções culturais, ideológicas, de poder, de pertencimento, entre outras. Todos esses são elementos de similitudes e diferenciação, mas também de afirmação e reconhecimento. São, portanto, elementos que alimentam e retroalimentam a produção da identificação e, por conseguinte, das próprias identidades.

É pela diferenciação e pelo encontro entre o "eu" e o "outro", que as identidades se estabelecem e se ramificam. Consiste na consciência da existência do outro enquanto sujeito portador de características que não são aferidas ao eu, mas que constituem o próprio universo do "Ser" ao qual enxergamos, seja pelas singularidades culturais e/ou ideológicas, pela função/atuação social, pelos projetos, etc.

Essas identidades são remetidas à ideia de objetivos comuns entre indivíduos em busca de afirmação e reconhecimento, podendo ser resultantes de ações religiosas e étnicas e da busca e posse por um dado território, mas podem estar associadas às relações de convivência, de sociabilidade e de 
familiaridade em um mesmo ambiente em que grupos e sujeitos se congregam residem e se afirmam enquanto "Ser"."

O vir a ser ou, em outros termos, o processo pelo qual "em quem nós podemos nos tornar" (HALL, 2006), tem a ver com processos de construção e ressignificação, com rotas que podem ser alteradas, preservadas ou reafirmadas no tempo-espaço. Mas nunca pode estar associado apenas ao tempo presente e às formas culturais do presente enquanto uma leitura de momento ou algo estanque. $\mathrm{O}$ ambiente de referência identitário e os sujeitos que o compõem são resultantes de uma "construção" relacional em diferentes momentos, envolvendo heranças, percepções, histórias de vida e idealizações que não são passíveis de entendimento apenas pela leitura do momento presente, do ser aí e agora. Aí estão impregnados os sedimentos da história, do tempo e de momentos vividos.

De tal modo, coaduna-se com a interpretação de que as identidades apresentam como principal característica as relações que se entremeiam ao universo material e simbólico, sem que isso ocorra de maneira antagônica (HAESBAERT, 1997; 1999). A existência da base material pode ser entendida como sendo o ponto de partida, a matéria-prima e/ou o espaço de referência que dá sentido à identidade e em que seus idealizadores produzem e ressignificam o espaço, o mundo vivido.

A esse respeito, Poche (1983) pioneiramente apresenta o chamado "espaço de referência identitária", ou seja, o espaço que compreende a concretude material e a base dos elementos simbólicos. Cruz (2007, p. 271) considera que é no espaço de referência identitário que "são forjadas as práticas materiais (formas de uso, organização e produção do espaço) e as representações espaciais que constroem o sentimento e significado de pertencimento dos grupos ou indivíduos em relação a um território".

A esse delineamento, Haesbaert (1997) endossa a leitura do papel das referências territoriais/espaciais no processo de construção e fortalecimento das identidades uma vez que estas referências são [...] "tomadas como relevantes para a identificação do[s] indivíduo[s]" (HAESBAERT, 1997, p. 50) e, também, das especificidades do território.

Neste sentido, a constituição das referências espaciais e, de tal modo, a constituição do território [...] "envolve sempre, ao mesmo tempo, mas em diferentes graus de correspondência e intensidade, uma dimensão simbólica, cultural, através de uma identidade territorial [...], e uma dimensão mais concreta" (HAESBAERT, 1997, p. 41).

\section{ESPAÇOS DE REFERÊNCIA DOS RIBEIRINHOS NO SERTÃO DO BAIXO RIO SÃO FRANCISCO}

$\mathrm{Na}$ composição das identidades inerentes às espacialidades ribeirinhas no Sertão do Baixo Rio São Francisco (Figura 1), buscou-se a aproximação com a classificação apresentada por Michel Bassand (1990) e da releitura deste realizada por Maria Geralda de Almeida (2008), uma vez que este, na compreensão das identidades e da cultura, leva em consideração o sentido do pertencimento e as transformações do ambiente que emergem pelas modificações dos modos de vida e pela articulação entre regiões.

São, portanto, cinco as tipologias identitárias estabelecidas na classificação apresentada por Bassand (1990): i) apáticos e resignados; ii) migrantes potenciais; iii) modernistas; iv) tradicionalistas e v) regionalistas. A leitura das identidades realizada por essa classificação tipológica já foi realizada por Almeida (2008) considerando a diversidade paisagística e territorial do Brasil Sertanejo e as chamadas "etnoterritorialidades" dos sertões.

A essa proposta de classificação, longe da tentativa de enquadrar os povos e seus modos de relacionamento com o ambiente, acarreia a possibilidade de pensar as identidades e suas respectivas espacialidades num contexto em que coexistem pessoas, formas, conteúdos, interesses e significações das mais variadas. Para a leitura e classificação das tipologias apresentadas utiliza-se como espaço de referência as comunidades, sedes municipais e povoados localizados às margens alagoana e sergipana do baixo rio São Francisco e que estão inseridas no domínio das terras semiáridas localizadas a jusante do lago da usina hidroelétrica de Xingó.

1 O sentido do "ser" aqui apresentado refere-se ao sentido existencial apresentado na filosofia de Maurice Merleau-Ponty (1996), em sua obra Fenomenologia da Percepção.

$\begin{array}{llllll}\text { Caminhos de Geografia } & \text { Uberlândia-MG } & \text { v. 23, n. } 85 & \text { fev./2022 } & \text { p. 42-53 } & \text { Página } 46\end{array}$


Figura 1 - Sertão do Baixo Rio São Francisco - Alagoas/Sergipe: localidades visitadas, 2018-2019

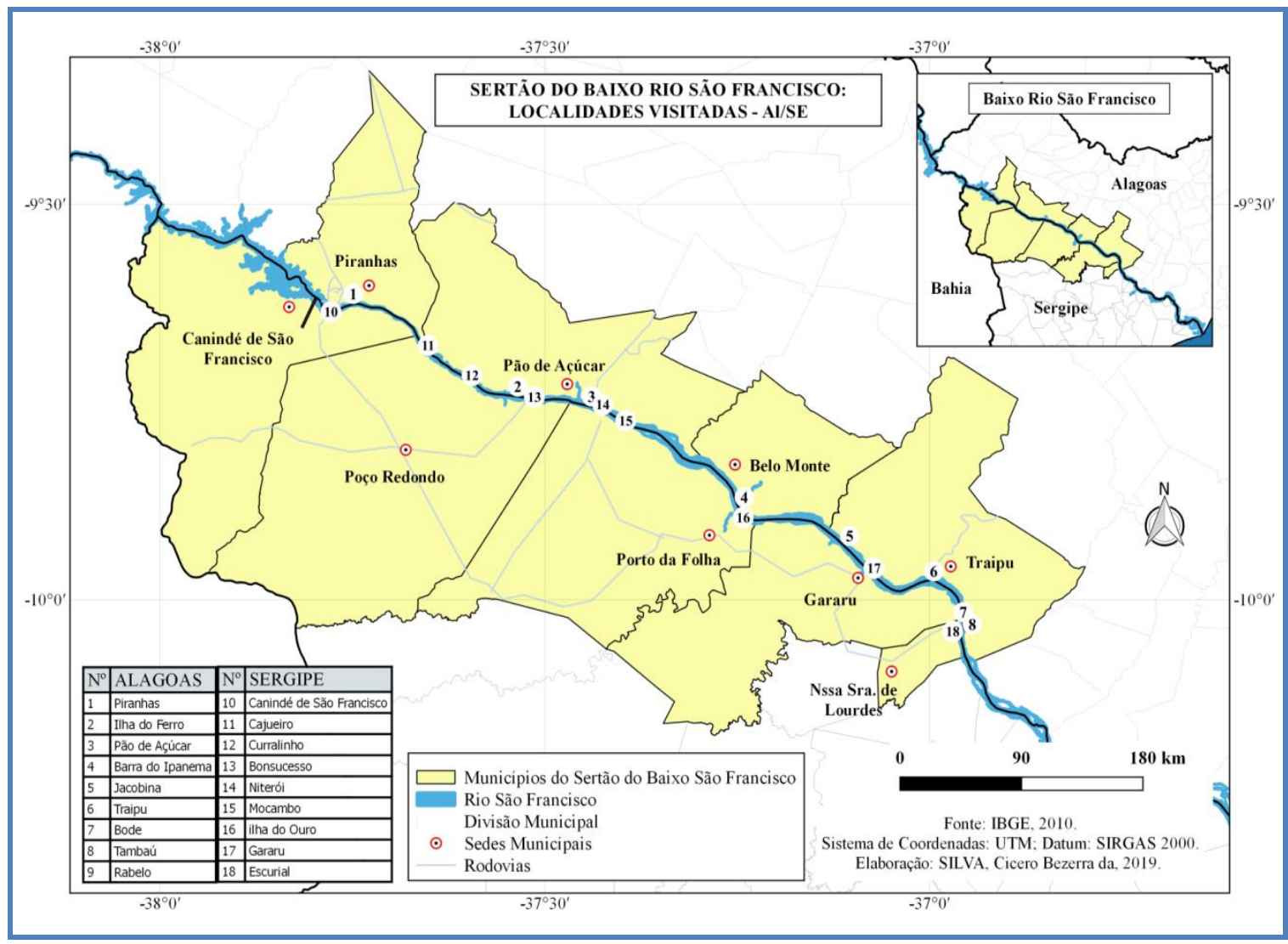

Fonte - IBGE, 2010. Elaboração: SILVA, Cícero Bezerra da, 2019.

Ao buscar uma classificação identitária para o Sertão do Baixo Rio São Francisco, não foi cogitada a pretensão de determinar formas de identificação, nivelar as experiências ou construir uma tipologia específica. Foi hábil, ainda, perceber que a macroidentidade está no ser ribeirinho e no ser sertanejo como construção emoldurada nas relações de pertencimento e no enraizamento, conforme já averiguado por Vargas $(2018 ; 2020)$ e Silva (2020). Além disso, o processo de ocupação do rio São Francisco revela a diversidade de povos, culturas e identidades que juntas congregam a riqueza da natureza do rio e que nele constituíram suas identidades que são diversas e múltiplas, pensamento esse muito bem formulado e discutido por Oliveira ${ }^{2}$ (2009), Souza ${ }^{3}$ (2013), Chagas ${ }^{4}$ (2014) e, mais recentemente, por Vargas ${ }^{5}$ (2020).

A dinamicidade de interação com a natureza local que se insere num quadro regional, a percepção, as territorialidades e 0 pertencimento, as falas e o contexto inerente à diversidade paisagística formam as expressões concretas, os traços fisiográficos e simbólicos definidores da apreensão e do agrupamento das tipologias identitárias apresentadas no quadro 1. São, como considerado por Almeida (2008, p. 61), "traços gerais" que compõem o universo dos povos sanfranciscanos.

A essa proposta de classificação se deve a possibilidade de envolver, na leitura das identidades, elementos de base tradicional e contemporâneos, significados e ressignificados de acordo com as formas de uso e de apropriação do rio São Francisco (Quadro 1). Dos tradicionalistas que têm os modos de vida associados aos ciclos da natureza até os modernizadores que se apropriam e transformam a natureza local em recurso, todos compõem o cenário e a vida no Sertão do Baixo Rio São Francisco e envolvem o ambiente e as formas do rural e do urbano.

${ }^{2}$ Ao apresentar em sua dissertação a diversidade identitária dos povos do rio São Francisco pela ótica das vozes dos vapozeiros e remeiros do rio.

${ }^{3}$ Tese que discute os vínculos territoriais nas margens e ilhas do médio rio São Francisco.

4 Ao apresentar uma narração em primeira pessoa a multiplicidade de povos, paisagens e lugares que constituem o rio São Francisco, inclusive em um contexto histórico.

${ }^{5}$ Ao indagar, pioneiramente, os "outros sentidos de ser ribeirinho", avançando para além das margens do rio São Francisco.

$\begin{array}{llllll}\text { Caminhos de Geografia } & \text { Uberlândia-MG } & \text { v. 23, n. } 85 & \text { fev./2022 } & \text { p. 42-53 } & \text { Página } 47\end{array}$


Quadro 1 - Tipologias identitárias no Sertão do Baixo rio São Francisco ${ }^{6}$ - AL/SE

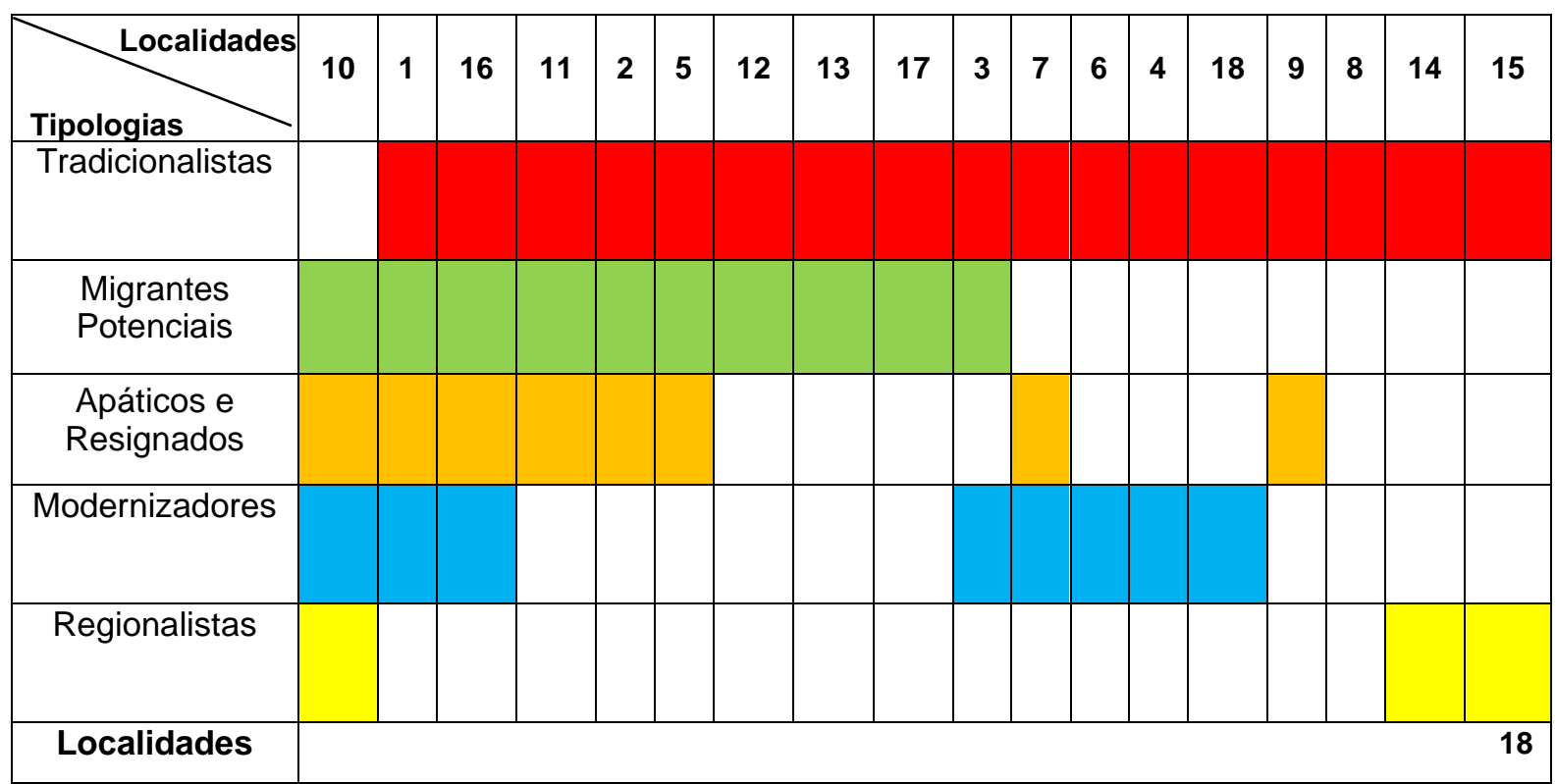

Fonte - Coleta de campo, 2018-2019.

Elaboração: SILVA, Cícero Bezerra da, 2019.

Com efeito, contextualizando as tipologias identitárias, o que se percebe no quadro é um amplo domínio do grupo representado pela classe dos tradicionalistas, fato que se coliga à afirmação de que, embora o baixo rio São Francisco tenha passado por significativas transformações ambientais, fisiográficas, econômicas, políticas e culturais, sobretudo no desenrolar das primeiras décadas do século XX, conforme considerado por Vargas (1999), as relações tradicionais e históricas dos povos com o rio continuam pujantes.

A constituição identitária dos tradicionalistas está associada aos grupos que, em sua composição, "são dotados de uma identidade histórica, patrimonial e emblemática muito forte [...] segundo um modelo antigo de caráter mítico" (ALMEIDA, 2008, p. 60). Junto a isso, constitui a existência simbólica e material dessa composição identitária o enraizamento, os sentidos do pertencimento, as práticas tradicionais e a peculiaridade de organização da vida cotidiana. Ainda inerente ao Sertão do Baixo Rio São Francisco, percebe-se também os cultivos da terra, as relações ecológicas e mitológicas, a religiosidade, o contexto das navegações e embarcações típicas e demais práticas culturais. Todos esses elementos fazem parte das espacialidades e da constituição das identidades no sertão do baixo rio São Francisco.

No que concerne à organização da vida dos povos identificados como tradicionalista e que povoam a dimensão rural e urbana no/do baixo rio São Francisco, eles têm suas histórias de vida amalgamadas ao rio. Guardam na memória as lembranças e heranças de um modo de vida específico, ligado, sobretudo, aos ciclos das águas do rio. Em suas percepções, estão impregnados modos de pensar, de sentir e de ser ribeirinho do rio São Francisco ou, como dizem, de ser beradeiro ou mesmo caboclo.

Nasci e me criei na beira do rio, no Mocambo, no trabalho criei meus filhos, a família [...]. Aqui na beira do rio eu tenho um bom viver, eu e a família quilombola. [...] Aqui eu sou um beradeiro, quem é beradeiro nem morre afogado e nem de sede (Entrevista realizada na comunidade quilombola Mocambo, município de Porto da Folha, margem sergipana, outubro de 2018).

Nesta tipologia encontra-se assentada a multiplicidade de povos e comunidades tradicionais que vivem e resistem historicamente entre as margens do grande rio ${ }^{7}$, o "Nilo Caboclo8", a "Artéria do

${ }^{6} \mathrm{~A}$ ordem numérica descrita no quadro corresponde ao conjunto de localidades visitadas nos trabalhos/jornadas de campo entre os anos de 2018 e 2019 as quais se encontram descritas e representadas no mapa 1.

7 Expressão apreendida em Guimarães Rosa (1985), em Grandes Sertões: veredas_e Auguste de Saint-Hilaire (2004), em Viagens às Nascentes do Rio São Francisco.

${ }^{8}$ Expressão apreendida em Ab' Saber (1999), em Sertão e Sertanejo: uma geografia humana sofrida.

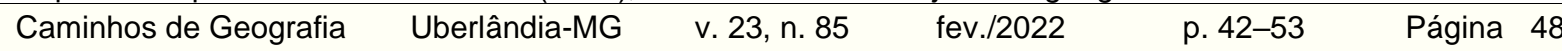


Sertão9". Trata-se, pois, nas palavras de Vargas (2020, p. 19), de [...] "identidades construídas pela materialidade das práticas vivenciadas e herdadas com o rio, com o meio, com a paisagem ribeirinha". Essa materialidade das práticas e das vivências com o rio e que se engendram nas paisagens construídas culturalmente são geradoras do sentimento de pertença que atribui ao rio o sentido de lugar. Está aí, portanto, o enraizamento ao rio São Francisco, o sentido existencial das identidades que fazem o ser ribeirinho tradicionalista.

[...] Eu posso dizer que o rio é o meu lugar. É o melhor lugar de viver. Eu nasci aqui, conheço tudo isso aqui. Só quem vive perto do São Francisco sabe o que é. É assim, aqui a vida passa mais devagar, ele [o rio] faz parte de mim,[...]. Não tem lugar melhor (Entrevista realizada em Gararu, margem sergipana, fevereiro de 2019).

No que diz respeito aos Migrantes potenciais, estes são "aqueles que não veem perspectiva de realização de seu projeto pessoal naquele território e estão buscando ocasiões para se migrarem" (ALMEIDA, 2008, p. 60). Desses, apreendemos, entre outros, os jovens funcionários de empreendimentos locais, como bares e restaurantes localizados entre as margens do rio São Francisco, e, também, jovens e moradores de povoados mais isolados ou distantes das sedes municipais.

$\mathrm{Na}$ margem alagoana, destaca-se o "encontro" do conformismo com a realidade local que se expressa em falas desconectadas da cultura e da identidade ou mesmo do apego ao lugar. A potencialidade da possível migração de jovens em ambas as margens é, sobretudo, apreendida na fala dos pais ao apresentarem incentivos de saída da realidade vivida no rio, saída essa que é justificada pela necessidade de estudar e/ou de trabalhar. Dos argumentos e justificativas, observouse: [...] "vai sair pra estudar, se quiser voltar depois, aí volta, mas tem que ir" [...] (Entrevista realizada em Bonsucesso, povoado da margem sergipana, janeiro de 2019), ou ainda: "Quem é jovem não dá pra ficar aqui, não, tem que sair. Não dá mais pra viver só do rio, peixe não tem. Então a saída é procurar fora. Eu não aconselho quem é novo ficar aqui, já tive vontade de ir embora, mas depois de velho não vou, não dá" (Entrevista realizada em Piranhas, margem alagoana, janeiro de 2019).

Elemento importante a ser considerado é o fato de que na tipologia dos migrantes potenciais é possível identificar uma especificidade fundamental à compreensão das identidades. $O$ sentido potencial da migração não é homogêneo: de um lado, estão aqueles que não veem perspectiva de futuro no local e, de outro, aqueles em que o devir está em sair e, após algum tempo, voltar. Nesse último grupo, o devir, ou seja, o vir a ser, é marcado pelo enraizamento e pelo sentido de lugar. Voltar "às bases", ao povoado, à cidade e ao rio São Francisco é o desejo desses jovens. Nessa perspectiva, o enraizamento se aproxima da tipologia dos tradicionalistas. Essa característica, portanto, revela e reafirma a multiplicidade contextual das identidades, como apresentado nas contribuições de Hall (2006), Castells (2006) e Cruz (2007).

Ao discorrer sobre a constituição das identidades das gentes que migram, Santos (2008) chama atenção para o fato de que o processo migratório envolve elementos da cultura e da própria constituição dos territórios e dos lugares em que a vida se realiza. Os sentimentos de pertencimento, embora possam ser afetados com o processo de migração, "estão fortemente vinculados aos territórios de origem. [...] Desse modo, é importante considerar que a migração envolve complexos processos de fixação de valores socioculturais" [...] (SANTOS, 2008, p. 98).

O grupo dos apáticos e resignados, em sua constituição identitária, é representado por aqueles que "destacam-se pela atitude passiva e por não se identificarem com os interesses locais e territoriais" (ALMEIDA, 2008b, p. 60). A apreensão dessa tipologia identitária se deu pela observância em relação ao contexto do desinteresse inerente às questões locais ou mesmo pelo conformismo com a realidade. São, em geral, jovens e adultos que não apresentam identificação cultural direta com o rio, muito embora as experiências de vida se façam no próprio rio São Francisco. No mesmo grupo tipológico, estão aqueles que têm o rio como fonte de renda, vivem dele e nele trabalham, todavia não possuem vínculos afetivos.

Ainda no que se refere à tipologia identitária dos apáticos e dos resignados, se observa que, na apreensão desse grupo pelo contexto das entrevistas ou mesmo pelo breve período de tempo e contato, poderá haver associações dos mesmos com outros grupos identitários, principalmente aqueles identificados como migrantes potencias. Isso se deve ao fato de que perceber e interpretar o contexto da identidade exige profundo envolvimento com a realidade vivida dos sujeitos e com os sentidos perceptivos, a fim de se estabelecer primeiro como sujeito participante da vida cotidiana.

${ }^{9}$ Expressão apreendida em Donald Piersom (1972), em O Homem no Vale do São Francisco.

$\begin{array}{lllll}\text { Caminhos de Geografia } & \text { Uberlândia-MG } & \text { v. 23, n. } 85 & \text { fev./2022 } & \text { p. 42-53 }\end{array}$ Página 49 
O contexto de representação dos modernizadores se dá pelo grupo que normalmente "forma a parcela bem sucedida na política e na economia local e são, quase sempre, depreciadores do patrimônio e da história local que consideram como tradições obsoletas e retardatárias" (ALMEIDA, 2008, p.60). No SBRSF, essas características podem ser observadas principalmente em Canindé de São Francisco/SE e Piranhas/AL. Essas são áreas tradicionalmente ocupadas por empreendimentos de turismo e lazer, associados ao lago da Usina Hidroelétrica de Xingó, às rotas do cangaço e suas trilhas na caatinga e ao patrimônio histórico e natural da chamada "Piranhas Velha".

A circulação fluvial de modernas embarcações de lazer e de turismo no rio São Francisco divide a paisagem com as chácaras e casas de veraneio entre as duas margens a ponto de que também coexistem, em um mesmo espaço, formas mais tradicionais de navegação e de pesca. Essa forma de apropriação do rio é revelada ainda pela ocupação das margens por estruturas de bares e restaurantes tanto nas sedes de municípios quanto nos pequenos povoados.

No limiar entre o "novo" e o "tradicional", essa tipologia identitária se revela pelas relações de poder fortemente associadas à apropriação material das estruturas naturais e construídas. A expansão das estruturas e empreendimentos supracitados associadas à observação da paisagem local de influência regional e ao contexto das entrevistas, revelam a condição de paisagens dominantes e dominadas ${ }^{10}$ como processo de exclusão, apropriação e subalternização de modos de vida e de uso das terras de beira-rio e das águas. Desvela-se aí, portanto, um rio que é território de apropriação material e política, de usos e interesses múltiplos, tanto quanto são múltiplos os povos que o habitam.

O grupo com menor expressividade observado no quadro das tipologias identitárias e apreendido no Sertão do Baixo Rio São Francisco está representado pelos regionalistas. Estes "preconizam o desenvolvimento autônomo de sua região a qualquer preço e mediante o recurso de qualquer meio, uma vez que consideram asfixiante o centralismo do estado" (ALMEIDA, 2008, p. 60). Sobressai-se para essa tipologia os presidentes de associação de moradores e colônia de pescadores, estruturas essas que são intensamente marcadas pelas lutas políticas e pela busca de ideais que sejam comunais ao contexto local de suas respetivas representatividades.

Desse feito, a marcante característica das falas politizadas foram os fundamentos da apreensão. A leitura dos espaços de vivência ou, de outro modo, das espacialidades ribeirinhas no Sertão do Baixo Rio São Francisco como espaço produtivo e de embates políticos, conflitos de uso e apropriação, são alguns dos elementos apreendidos. O contexto da política local, associado às gestões municipais, foi delineador das reflexões que encadeiam o "discurso" ambiental e suas relações com órgãos e instituições tais como o Instituto de Meio Ambiente de Alagoas (IMA), o Instituto de Meio Ambiente e Recursos Naturais Renováveis (IBAMA), a Companhia de Desenvolvimento do Vale do São Francisco (CODEVASF), as secretarias municipais de meio ambiente e cultura, entre outros.

Desse grupo identitário, as reivindicações associadas às demandas locais ganham espaço, sobretudo em Canindé de São Francisco/SE, povoado Niterói/SE e Gararu/SE. Na margem alagoana, o contexto do sítio urbano de Piranhas associa-se ao de Canindé de São Francisco/SE, inclusive com apontamento entre as duas localidades. São, majoritariamente, apontadas as questões econômicas que envolvem a política local, a pesca e as lideranças de associações e colônias de pescadores.

Pensadas em suas totalidades, todas essas tipologias identitárias têm como referência o rio São Francisco e se fazem pela apropriação simbólica e material do espaço que ora apreende-se como lugar, ora como território. Pensado pela apropriação simbólica, pelas relações de pertencimento e enraizamento, o rio é o lugar de ser e de estar. Um espaço existencial, o lugar da vida. O lugar da identidade do ribeirinho.

\section{A (RE)PRODUÇÃO DA ESPACIALIDADE RIBEIRINHA}

Quais elementos são constitutivos da espacialidade ribeirinha? Para responder a essa indagação recorremos ao pensamento de Vargas (2018, p. 22), ao desvelar no rio São Francisco "a paisagem que se renova e se ressignificado [...] uma paisagem que se requalifica sob novas relações sociopolíticas" [...]. Com isso, o processo de produção e reprodução da espacialidade ribeirinha está entremeado entre a dimensão da apropriação simbólico-subjetiva e material que revela modos de usos e de significação do ambiente rio tomado com os sentidos de lugar e de território.

10 Tipologias de paisagem apresentadas Denis Cosgrove em A Geografia está em Toda Parte: cultura e simbolismo nas paisagens humanas.

$\begin{array}{llllll}\text { Caminhos de Geografia } & \text { Uberlândia-MG } & \text { v. 23, n. } 85 & \text { fev./2022 } & \text { p. 42-53 } & \text { Página } 50\end{array}$


Sendo lugares e territórios, essas relações sociopolíticas (VARGAS, 2018) se estabelecem no cotidiano da vida ribeirinha como geradoras de espacialidades que são reverberadas nos modos de ser, pelas relações de sociabilidade e constituição das próprias identidades. Pela materialidade ou simbolismo, os modos de apropriação refletidos na constituição identitária são ressignificados pelas funções e usos e, com isso, ocorre a produção de uma consciência socioespacial de pertencimento acarreada à produção e reprodução das representações e práticas constituintes das respectivas espacialidades.

Como bem apontado por Cruz (2006, p. 41), o processo de afirmação identitária como processo de identificação se dá pelas práticas e representações espaciais. Assim sendo, "é na relação dialética entre domínio e apropriação, entre vivido e concebido que é construída a consciência socioespacial do pertencimento".

E acrescenta:

\begin{abstract}
No que diz respeito à consciência do pertencimento a uma lugar, a um território, essa é construída a partir das práticas e representações espaciais que envolvem ao mesmo tempo o domínio funcional-estratégico sobre um determinado espaço (finalidades) e a apropriação simbólico/expressiva do espaço (afinidades/afetividades) (CRUZ, 2006, 40).
\end{abstract}

Desse entendimento, percebe-se então que a unidade dialética entre o domínio e a apropriação e as relações do vivido reportadas à apropriação mais simbólica constituintes do espaço de referência do rio São Francisco e, de tal modo, da espacialidade ribeirinha, são formadores de lugares e territórios e de suas respectivas afirmações identitárias.

Como lugar, a formação da espacialidade ribeirinha está ancorada nas relações de pertencimento e no enraizamento, fortemente associadas às histórias de vida, aos modos tradicionais de cultivo, de uso das águas e da própria navegação com embarcações típicas, tradicionais. Assim sendo, o riolugar é a expressão mais concreta e subjetiva do ser ribeirinho e do estar no rio São Francisco.

Um lugar com dimensões e sentidos ambivalentes, um lugar que é fluido e que tem acompanhado a dinâmica das transformações do rio, das várzeas, da vazão das águas e das próprias histórias de vida. Um rio-lugar que se faz nas memórias individuais e coletivas, mas, também, nos significados das vivências, nos símbolos, na religiosidade, nas paisagens transbordantes de significações, nas lendas, mitos e personagens do São Francisco. Lugar-rio ou rio-lugar demarcado pela afirmação de valores, de sentimento de pertencimento no sentido mais profundo do termo.

Como território, a formação da espacialidade ribeirinha ancora-se no sentido da apropriação simbólica, territórios construídos e significados como lugar, são os territórios de vida. Desses, destaca-se o conjunto de povos indígenas, quilombolas e comunidades ribeirinhas com seus espaços demarcados e simbolicamente apropriados e significados. Esses povos, originários ou não, em seus respectivos espaços, nos abrilhanta Medeiros (2009, p. 219), [...] vai [sic] produzindo seus próprios símbolos, suas identidades, cria suas próprias significações [...] coloca valores relacionados aos sentimentos e à identidade cultural".

Depois, há de ressaltar a apropriação do Sertão do Baixo Rio São Francisco pelas políticas de governo (VARGAS, 1999; 2018); assentamentos de reforma agrária (VARGAS, 1999; MATOS, 2015); estabelecimentos de empreendimentos comerciais entre as margens, fixação de empresas de turismo e lazer, uso privado - apropriação - de ilhas formadas e em formação, bem como ocupação de suas margens pela "explosão" de chácaras e residências (SILVA, 2020); assim como pelo crescente emaranhado de redes de adutoras para abastecimento de água em Sergipe e Alagoas (VARGAS, 2020) e relações conflituosas pelo uso da terra e das águas (COMISSÃO PASTORAL DA TERRA, 2018; SILVA, 2019). Todas essas formas de uso e apropriação são elementos constitutivos da espacialidade ribeirinha no Sertão do Baixo Rio São Francisco e que coexistem entre o que, grosso modo, denominados de relações tradicionalistas e modernizadoras.

Qualificadoras do espaço de vivência e atuação dos ribeirinhos, essas espacialidades consubstanciam-se entre materialidade e simbolismo, resultado da constituição das identidades ribeirinhas e dos níveis culturais de apropriação.

\title{
CONSIDERAÇÕES FINAIS
}

Problematizar e analisar o Sertão do Baixo Rio São Francisco pela leitura das identidades exigiu, entre outros condicionantes, a compreensão de que as identidades são múltiplas tanto quanto é 
múltipla a diversidade dos povos que historicamente ocupam suas margens. Lançar mãos dessa leitura delineou o entendimento de que os processos de identificação, a própria identidade, são formados e constituídos no espaço e no tempo como sedimentos de processo pretéritos que são/podem ser materializados no presente e transformados em aspirações futuras. É, portanto, o que se foi, o que ficou, o que se é e aquilo que pode, quiçá, vir a ser.

$\mathrm{Da}$ constituição das tipologias identitárias apreendidas pelas falas/relatos e observações nas comunidades rurais e urbanas e nas sedes municipais nas margens alagoana e sergipana, destacase a pujança dos vínculos territoriais com o rio São Francisco nos lugares de fala e de vida. De modo mais especifico, o enlace pelo pertencimento e enraizamento ao rio encontra-se claramente representado pela tipologia identitária dos tradicionalistas.

Ademais, sob a ótica das tipologias identitárias identificas no Sertão do Baixo Rio São Francisco, todas estão ancoradas aos processos de mudanças e permanências as quais o rio e seus povos foram e são submetidos, associados claramente as novas funções do rio, aos modos de apropriação. Fato este que se revela como delineador de práticas, estratégias e usos definidores das espacialidades e dos campos de atuação de cada sujeito, de cada ribeirinho.

Mediante o contexto apresentado, a constituição das identidades ribeirinhas, bem como de suas respectivas especialidades ocorrem de modo dinâmico, diferenciando-se de um dado estático e acabado. A dinâmica fluvial, os ciclos de vida e das águas do rio São Francisco, a permanência das tradições e a perspectiva do que pode vir a ser, as aspirações de futuro e pluralidade de usos e significações do rio revelam essa dinâmica que se reverbera na constituição identitária e na (re)produção da espacialidade ribeirinha que se faz e refazem entre lugares e territórios de vida, disputas e usos múltiplos.

\section{AGRADECIMENTOS}

Ao Concelho Nacional de Desenvolvimento Científico e Tecnológico, pela concessão de bolsa de mestrado com vigência de um ano. À Universidade Federal de Sergipe e ao Programa de Pós-graduação em Geografia, pelo fornecimento de transportes e diárias para realização dos trabalhos de campo. Aos ribeirinhos do Sertão do São Francisco, pelo acolhimento e apoio nas comunidades, em suas residências e nas travessias entre as margens do rio São Francisco.

\section{REFERÊNCIAS}

ALMEIDA, M. G. Etnogeografia do Brasil Sertanejo. In: SERPA, Ângelo (Org.). Espaços culturais: vivências, imaginações e representações [online]. Salvador: EDUFBA, 2008.

BASSAND, M. Culture et Régions d'Europa. Lausanne - Suíça: Tresses Polytechniques et Universitaires Romands, 1990.

BENÍTEZ, G. L.; LEVI, L. L. Entre el Arraigo y la Exclusión: fragmentaciones sociales, yuxtaposiciones territoriales en San Gregorio Atlapulco, México. In: ALMEIDA, M. G. (Org.). Territorialidade na

América Latina. Goiânia: UFG, 2009.

CASTELLS, M. O Poder da Identidade. São Paulo: Paz e Terra, 1999.

COSGROVE, D. A Geografia Está em Toda Parte: cultura e simbolismo nas paisagens humanas. In: CORRÊA, Roberto Lobato; ROSENDAHL, Zeny (Orgs.). Geografia Cultural: uma ontologia. Rio de Janeiro: EdUERJ, 2006.

COMISSÃO PASTORAL DA TERRA (CPT). Centro de Documentação Dom Tomás Balduino (CEDOC). Conflitos Pela Água (2009 - 2017). Disponível em: https://www.cptnacional.org.br/cedoc. Acesso em: nov. de 2018.

CRUZ, V. C. Itinerários Teóricos Sobre a Relação Entre Território e Identidade. In: BEZERRA, Amélia Cristina Alves; ARRAIS, Tadeu Alencar (Orgs.). Itinerários Geográficos. Niterói: EdUFF, 2007.

Pela Outra Margem da Fronteira: território, identidades e lutas sociais na Amazônia. Dissertação (Mestrado em Geografia) - Universidade Federal Fluminense. Rio de Janeiro, 2006.

DOURADO, A. M. Viver e Pertencer: identidades e territórios nos assentamentos rurais em Sergipe. Tese (Doutorado em Geografia) - Universidade Federal de Sergipe. São Cristóvão, 2014.

HAESBAERT, R. Identidades Territoriais. In: RODENDHAL, Zeny. CORRÊA, Roberto Lobato. (Orgs.). Manifestações Culturais no Espaço. Rio de Janeiro: EDUERJ, 1999.

p. 42-53 Página 52


1997.

Des-territorialização e Identidade: a "rede" gaúcha no Nordeste. Niteói-RJ: EDUFF

HALL, S. Identidade Cultural na Pós-Modernidade. 11. ed. Rio de Janeiro: Imprensa do Brasil, 2006.

MEDEIROS, R. M. V. Território, espaço de identidade. In: SAQUET, Marcos Aurélio; SPOSITO, Eliseu Saverino (Orgs.). Territórios e Territorialidades: teorias, processos e conflitos. São Paulo: Expressão Popular, 2009.

MERLEAU-PONTY, M. Fenomenologia da Percepção. São Paulo: Martins Fontes, 1996.

PIERSOM, D. O Homem no Vale do São Francisco. Rio de Janeiro: SUVALE, 1972. Tomo I.

POCHE, B. La Región comme espace de reférénce identitaire. Espaces et Societés, Paris, n. 42, 1983.

ROSA, Guimarães. Grande Sertão: veredas. 20. ed. Rio de Janeiro: Nova Fronteira, 1986.

SAINT-HILAIRE, A. Viagens às Nascentes do Rio São Francisco. Belo Horizonte: Editora Itatiaia, 2004.

SANTOS, M. A Natureza do Espaço: técnica e tempo, razão e emoção. São Paulo: Hucitec, 2002.

SANTOS, R. J. (RE) Ocupação do Cerrado: novas gentes, outras identidades. In: ALMEIDA, M. G.; CHAVEIRO, E. F.; BRAGA, H. C. (Orgs.). Geografia e Cultura: os lugares da vida e a vida dos lugares. Goiânia: Editora Vieira, 2008.

SERRES, M. Atlas. Lisboa: Editions Juliard, 1994.

SILVA, C. B. Entre Margens, Terras e Gentes: convivialidades e identidades no Sertão do Baixo rio São Francisco. Dissertação. (Mestrado em Geografia). Programa de Pós-graduação em Geografia da universidade Federal de Sergipe. São Cristóvão - SE: PPGEO/UFS, 2020.

2019. Conflitos Por Água no Brasil: panoramas na região semiárida. Boletim Dataluta, n.136,

SOUZA, A. F. G. Ser, Estar, Permanecer: vínculos territoriais das gentes que povoam as margens e ilhas do rio São Francisco. Tese (Doutorado em Geografia) - Universidade Federal de Uberlândia. Uberlândia-MG, 2013.

STOLL, É., et al. (Orgs). Paisagens Evanescentes: estudos sobre a percepção das transformações nas paisagens pelos moradores dos rios amazônicos. Belém: NAEA, 2019.

SUPERINTENDÊNCIA DE DESENVOLVIMENTO DO NORDESTE - SUDENE. Delimitação do

Semiárido. Disponível em: <http://www.sudene.gov.br/planejamento-regional/delimitacao-dosemiarido>. Acesso em: 09 jul. 2018.

TURATO, E. R. Decidindo Quais Indivíduos Estudar. In: Pesquisa Clínico-qualitativa. Petrópolis: Vozes, 2003.

(Org.). Tratado da Metodologia da

VARGAS, M. A. M. Os Ribeirinhos do Baixo São Francisco: outros sentidos de ser. Revista Geograficidade. V.10, n.1, 2020.

Vivências Culturais com o Rio São Francisco: certezas, entradas e caminhos. In: VARGAS Maria Augusta Mundim; SANTOS, D. L. (Orgs). Tempos e Espaços da Pesquisa Qualitativa. Aracaju: Criação: 2018.

Desenvolvimento Regional em Questão: o Baixo São Francisco revisitado. São Cristóvão-SE: UFS, 1999.

Recebido em: 14/09/2020

Aceito para publicação em: 31/10/2021 